\title{
O Aprender Organizacional: relato de experiência em uma unidade básica de saúde
}

\section{The Organizational Learning: report of an experience at a Basic Health Unit}

Maria Luciana Botti

Enfermeira da Secretaria Municipal da Saúde de Maringá, Aluna do Mestrado em Enfermagem, Departamento de Enfermagem, Universidade Estadual de Maringá.

E-mail: malubottiðyahoo.com.br

Maria José Scochi

Enfermeira. Doutora em Saúde Pública. Docente do Departamento de Enfermagem, Universidade Estadual de Maringá.

E-mail: mjscochiळuem.br

\section{Resumo}

O Sistema Único de Saúde (SUS) prevê que suas ações sejam desenvolvidas por uma rede regionalizada e hierarquizada de atenção à saúde, com tecnologias adequadas para cada nível, visando ao atendimento de saúde integral à população. Considera-se que a organização do SUS constrói-se principalmente pela implantação de redes de Unidades Básicas de Saúde (UBSs), objetivando priorizar as ações de atenção básica. Partindo da constatação de que o processo organizativo das UBSs é deficitário, da verificação de sua importância para o desenvolvimento do SUS e das dificuldades estratégicas que contemplem práticas de saúde voltadas para promoção da saúde coletiva e conseqüentemente de desenvolvimento da comunidade assistida, torna-se relevante apresentar experiências exitosas. No entanto, as UBSs, apesar de terem a mesma missão, desenvolverem os mesmos programas de saúde e serem guiadas pela mesma política de saúde, apresentam singularidades determinadas por importantes variáveis. Neste sentido, não pretende apresentar um modelo a ser seguido, e sim compartilhar idas e vindas de um processo balizado por dois princípios: a de que a participação coletiva é necessária para a transformação e de que o modelo de assistência à saúde deve ser o que atenda as reais necessidades da comunidade. Este artigo relata a experiência de aprendizado organizacional em uma UBS e visa contribuir para o desenvolvimento de processos de trabalho que busquem a efetividade do SUS. A metodologia do trabalho construiu-se pelo Método Altadir de Planificação Popular (MAPP), buscando-se a co-gestão e a efetivação do controle social.

Palavras-chave: Atenção Básica à Saúde; Unidade Básica; Aprendizado organizacional. 


\section{Abstract}

The Sistema Único de Saúde SUS (Unique Health System) subscribes that all heath actions must be taken by a regional and hierarchically health assistance network with an appropriate technology for each level focused in populations whole health treatment. In this report it is considered that the SUS is mainly constructed through the introduction of the Unidades Básicas de Saúde - UBSs (Health Basic Centers) aiming to the attention to the basic levels of Health demands. By the analysis of the faults of the UBS's organizational process, its importance for SUS's development and its difficulties by choosing appropriate strategies, which include solutions that deal with the promotion of common health and local development, it is extremely relevant to consider successful experiences. The UBSs, in spite of having the same objective, develop the same health programmes and being led by the same health politics, present singularities settled by important variables. This work doesn't aim to present a model to be used, but to share an experience followed by two principles: that the collective participation is necessary for the transformation and that the assistance model must be the one which supplies the community's real needs. Due to that, this work presents an experience with an organizational learning in a UBS and aims to contribute to the development of work processes that can lead to a more effective SUS. The method used was the Método Altadir de Planificação Popular - MAPP. (Altadir's Popular Planification Method) aiming to the cooperation and social control.

Keywords: Basic Level of Health Assistance; Basic Health Centers; Organizational Learning.

\section{Introdução}

O direito de todos os cidadãos brasileiros à saúde foi impulsionado, na década de 1980, por um amplo movimento nacional para uma reforma sanitária no país. Em decorrência desse processo foi instituído pela Constituição Federal de 1988 um sistema de saúde único, universal e equânime: o Sistema Único de Saúde (SUS).

O Ministério da Saúde, em seus documentos oficiais, assinala que "o SUS prevê que as ações de saúde devem ser desenvolvidas por uma rede regionalizada e hierarquizada de atenção à saúde, com tecnologias adequadas a cada nível de atenção, visando ao atendimento integral da população" (Brasil, 1999). Desta forma, considera-se que a organização do sistema público de saúde brasileiro constrói-se principalmente pela implantação de redes de Unidades Básicas de Saúde (UBSs), a forma mais regionalizada e hierarquizada de realização de ações no nível de atenção básica à saúde.

No entanto, semelhante ao que ocorre em outras áreas da administração pública, como educação, segurança e assistência social, o processo organizativo das UBSs ainda é deficiente, dificultando a concretização das políticas públicas.

"A organização da rede de serviços locais de saúde, tanto em termos quantitativos como qualitativos, representa um processo fundamental na reforma do setor saúde, mas é fortemente dependente do desempenho gerencial que leva as variações em termos de resultados e impactos na saúde da população" (Bodstein, 2002, p. 4004).

Assim, considerando a importância da organização das Unidades Básicas de Saúde para o desenvolvimento do SUS e as dificuldades em encontrar estratégias que contemplem práticas de saúde voltadas para promoção da saúde coletiva e desenvolvimento da comunidade local, o presente artigo traz um relato da experiência do aprendizado organizacional de uma UBS.

Não há neste relato pretensões de apresentar um modelo a ser seguido, mas de compartilhar idas e vindas de um processo balizado por dois princípios: a de que participação coletiva é necessária para a transformação da realidade concreta e de que o modelo de assistência à saúde deve atender às reais necessidades da comunidade. 


\section{Desafios do Processo Organizativo}

O processo organizativo de uma Unidade Básica de Saúde é quase sempre visto como a simples administração de poucos recursos humanos e materiais destinados ao funcionamento dos programas e estratégias formulados pelo nível central ${ }^{1}$. Essa forma de trabalho tende a uma atuação verticalizada, que não corresponde aos desafios dos compromissos com a construção de um modelo de assistência norteado pelos princípios de regionalização e descentralização propostos pelo SUS.

Sobre o fato de a UBS ser a "porta de entrada" do sistema de saúde, e as implicações decorrentes da natureza do trabalho de assistir a comunidade, podem-se destacar alguns pontos relevantes que interferem no seu processo organizativo.

0 primeiro deles refere-se justamente à proximidade com a comunidade, representando a materialização da "figura" do Estado, sendo comum as situações que envolvam atos de vandalismo, até mesmo danos à sua estrutura física. Verifica-se que essas ocorrências resultam do entendimento equivocado do equipamento público, caracterizado pela ausência do sentimento de pertencimento de alguns usuários ${ }^{2} \mathrm{em}$ relação à UBS e sua dificuldade em exercer a cidadania para o fortalecimento dos mecanismos de superação de uma realidade social identificada como opressora, indigna e degradante.

Em virtude dessa proximidade, determinadas formas de atuação da UBS podem torná-la alvo de políticas de caráter eleitoreiro, sendo até mesmo utilizada como produtora de votos e de articulação política local e municipal. Não é rara também a idéia de que a equipe de saúde é oponente da população, evidenciando ainda mais a falta de consciência com relação à estrutura organizativa dos serviços públicos e da possibilidade de participação de todos na transformação dessa realidade.

Um segundo ponto é que a assistência produzida na UBS, para ser resolutiva, depende diretamente do bom funcionamento dos outros níveis de atenção à saúde, como a média e a alta complexidade, e dos outros órgãos relacionados à saúde nas três esferas do governo.

Além disso, para que se garanta o princípio da integralidade da assistência, contemplado pelo SUS, faz-se necessária a consolidação de um sistema efetivo de referência e contra-referência, porque, embora a UBS tenha uma certa autonomia em relação às ações de prevenção - principalmente no que se refere à educação em saúde -, há uma interdependência de todo o sistema de saúde para o desenvolvimento da promoção, proteção, recuperação da saúde e garantia do caráter integral do cuidado.

0 terceiro ponto refere-se à atuação do mediador de processo organizativo ${ }^{3}$ na UBS e suas concepções, que podem determinar o cotidiano do trabalho. Alguns aspectos na composição dessas concepções podem ser relevantes para a atuação na organização da UBS como a práxis autoritária, o individualismo, a subjetividade, a internalização do pensamento normativo, e a suscetibilidade diante das pressões externas - a comunidade e do nível central.

A verticalização nas relações profissionais na UBS não é incomum, manifesta-se pela existência da diferente valorização social oferecida aos trabalhadores que integram a equipe, e pela centralização das decisões que interferem no processo organizativo, representação da práxis autoritária.

Sobre a concretização da práxis autoritária, Dias apud Peruzzo (1998) afirma que esta se concretiza a partir de um projeto de dominação política em todas as instâncias da vida social, expressão de um processo de ideologização que visa configurar a dominação como algo natural, não imposto pela força, à medida que integra à personalidade individual e à prática social cotidiana. Essa práxis, fruto de uma cultura positivista que domina o pensamento ocidental e de um modelo capitalista, conduz a um imaginário social que idolatra o axioma do individualismo.

Sobre os desdobramentos desta cultura assim formula Azevedo (2002, p. 356) que “(...) a atuação dos gerentes é construída na subjetividade, ou seja, nos

\footnotetext{
1 A expressão nível central será utilizada neste artigo para referir-se aos órgãos gestores em cada esfera de governo, ou seja, Secretaria Municipal, Secretaria Estadual e Ministério da Saúde respectivamente.

20 termo usuário neste artigo refere-se a todo indivíduo que utiliza os serviços de saúde.

3 Por mediador do processo organizativo compreende-se a figura do gestor local de saúde que em alguns municípios é conhecido como Diretor de UBS, Autoridade Sanitária Local, ou ainda Gerente de Centro de Saúde.
} 
processos de identificação, idealização e formação de fantasias inconscientes que atravessam o cotidiano dos grupos".

Essa análise de que a subjetividade vem à tona nas formas de organização do cotidiano de trabalho também é formulada por Uribe (2001, p. 210) da seguinte maneira: “(...) a subjetividade na gestão é um tema que está na ordem do dia em função da relativa crise da gestão procedimental e da emergência de uma nova visão que destaca a importância da cultura (na formulação dos objetivos organizacionais), da liderança comunicativa e da aprendizagem organizacional".

A internalização do pensamento normativo influencia as relações entre os trabalhadores, demonstrada pela rigidez do processo organizativo, desencadeando a negação da realidade encontrada nas comunidades.

A mediação do processo organizativo nas Unidades Básicas de Saúde pode resultar na pouca capacidade de resolver os problemas de saúde da comunidade, pois tende a se limitar à tentativa de responder as pressões exercidas tanto pelo nível central, em relação à execução dos programas, como pelas demandas dos usuários assistidos.

Os desafios das UBSs estão além dessa limitada mediação, pois apesar de terem a mesma missão, desenvolverem os mesmos programas de saúde e serem guiadas pela mesma política de saúde, apresentam singularidades determinadas por importantes variáveis para a constituição de um modelo local.

Assim, a mediação em um processo organizativo de UBS tem de estar atenta à natureza de um serviço de caráter público comprometido eticamente com os princípios do SUS. Do contrário, corre-se o risco de comprometer a saúde dos habitantes da área adstrita.

\section{A Participação da comunidade e a organização dos trabalhadores da UBS}

O processo organizativo de uma UBS depende significativamente da compreensão dos princípios norteadores do SUS, principalmente no que diz respeito à eqüidade e universalidade. Ao compreender esses princípios, a sua aplicação na organização da UBS representa a oposição às características das formas tradicionais e verticalizadas de trabalho.

Negar a participação decorrente da dinâmica das relações estabelecidas no processo de trabalho da UBS é negar as potencialidades de um processo organizativo essencialmente democrático. Neste sentido, concorda-se com Mehry (2002), quando afirma que "todos governam em uma organização, há 'agentes da organização’ que estão em posição de alta direção, e há 'agentes' que ocupam todos os outros espaços de ação na organização, mas que governam também”.

Inicialmente, a escolha de uma metodologia de trabalho para a organização da UBS representou uma possibilidade de sistematizar os desafios para que as ações não representassem desejos pessoais ou uma "ordem" do nível central, mas a vontade da maioria dos atores sociais envolvidos.

$\mathrm{Na}$ busca por esta metodologia descobriram-se incertezas sobre o conhecimento teórico de processos organizacionais, apesar do grande número de estudos, pesquisas e artigos publicados a respeito, porém uma certeza se confirma, a de que o processo organizativo está intimamente vinculado ao planejamento.

No Brasil, o planejamento em saúde desenvolveuse a partir da de 1960 e foi marcado pelo pensamento normativo, que ainda hoje influencia os modelos de gestão em saúde. Entretanto, passa assumir novas características na década de 80 , com o crescente acúmulo de problemas no setor saúde e pelo movimento da reforma sanitária, sendo principalmente influenciado pelo pensamento matusiano ${ }^{4}$.

Com base nesse pensamento, vislumbrou-se o planejamento como ferramenta imprescindível do processo organizativo da UBS identificando-se, assim, um método possível de ser aplicado, o MAPP - Método Altadir de Planificação Popular.

A partir da definição metodológica, uma nova preocupação surgiu: a adesão dos atores sociais à proposta de desenvolvimento do planejamento, uma vez que esta é uma das condições para a sua aplicabilidade.

Para a aplicação do MAPP, percebeu-se a existência de alguns possíveis obstáculos que poderiam difi-

\footnotetext{
40 pensamento matusiano é atribuído a Carlos Matus, teórico do Planejamento Estratégico Situacional, que segundo Huertas, (1996) "define planejar como ato de pensar antes de agir, pensar sistematicamente, com método; explicar cada uma das possibilidades e analisar suas respectivas vantagens e desvantagens; propor objetivos".
} 
cultar a adesão imediata dos trabalhadores da UBS e dos usuários, como:

- falta de interação entre os trabalhadores, ou seja, a existência de dois ou mais subgrupos de trabalho, com interesses diferentes conduzindo as ações para lados opostos;

- o relacionamento distante e desarticulado entre trabalhadores e comunidade, o que caracterizava disputas marcadas por reclamações de ambas as partes;

- a existência de um modelo de assistência médicocentrado, que impedia o bom andamento das ações desenvolvidas pelas equipes de saúde da família;

- a acessibilidade de assistência reduzida unicamente ao agendamento de consultas médicas;

- a inexistência de espaço próprio para reuniões entre os trabalhadores da UBS e a comunidade com a finalidade de discutir questões relacionadas ao atendimento e buscar soluções coletivas.

De acordo com a problemática encontrada, entendeu-se que seria necessário utilizar estratégias que sensibilizassem os atores sociais para a construção de um processo coletivo de trabalho, capaz de implantar e implementar ações fortalecedoras de um novo modelo de assistência coerente com as necessidades locais.

De acordo com Merhy (2002), a composição de uma caixa de ferramentas para governar deve conter essencialmente saberes de como as coisas devem ser feitas, o que remete para a compreensão do próprio saber fazer, como uma tecnologia vital para o agir governamental. Buscou-se anteriormente à definição das estratégias, elencar alguns objetivos definidores (caixa de ferramentas) para as ações organizativas da UBS:

- Desenvolver a participação e a construção coletiva.

- Conferir responsabilidades para todos os atores sociais envolvidos, estabelecendo representações efetivas das categorias profissionais.

- Implementar o controle social.

- Garantir periodicamente um espaço coletivo de discussão com a participação de todos os trabalhadores da UBS e representantes dos usuários, para a realização do planejamento local.

- Desenvolver ações intersetoriais para a promoção de saúde nos bairros de abrangência da UBS.
As estratégias utilizadas teriam que articular os conceitos de promoção, prevenção e recuperação da saúde, desenvolvimento de recursos humanos e fortalecimento do controle social, buscando a construção de um trabalho que representasse o respeito à coletividade e o compromisso com os princípios do SUS.

Assim após a determinação dos objetivos foi possível encontrar as seguintes estratégias para o desenvolvimento do processo organizativo da UBS:

- Realizar encontros para o desenvolvimento da cidadania - a saúde como um direito de todos.

- Implantar o colegiado gestor da UBS.

- Organizar reuniões de caráter permanente e com a participação de todos os trabalhadores da UBS.

- Fortalecer o Conselho Local de Saúde.

- Implantar processo de educação permanente aos trabalhadores da UBS.

- Estabelecer parcerias com lideranças comunitárias.

Ao objetivar o desenvolvimento da participação e da construção coletiva, conferindo responsabilidades aos atores sociais envolvidos, verificou-se a necessidade de incentivar a participação e o exercício da cidadania pelos conselheiros locais de saúde, usuários do serviço e trabalhadores da UBS.

As raízes históricas da participação, formuladas por Peruzzo (1998) ilustram a necessidade de incentivo:

"Nas condições do Brasil e de outros países latinoamericanos, onde os povos não têm tradição nesse sentido, aliado isto à reprodução de valores autoritários, à falta de conscientização política e a outros fatores, pretender alcançar um grau de participação mais elevado é algo de difícil concretização. Em nosso caso, desde o período colonial, nos foi obstada ou até usurpada a possibilidade de avançar nessa prática. Nossas tradições e nossos costumes apontam mais para o autoritarismo e a delegação de poder do que para assumir o controle e a co-responsabilidade na solução dos problemas"(Peruzzo, 1998, p. 73).

Nesse sentido, foram realizados encontros com os conselheiros, trabalhadores e usuários da UBS, utilizando-se a metodologia problematizadora que, por meio de dinâmicas de grupo, motivaram as discussões e os debates em torno das questões de saúde locais.

Os encontros foram realizados durante a semana, no período noturno, e aos sábados, no período da tar- 
de, para que a população pudesse participar de forma mais ativa. Os agentes de saúde distribuíram convites no bairro e pessoalmente explicaram o objetivo dos encontros para as famílias.

Do primeiro encontro participaram 25 pessoas, entre trabalhadores, usuários e conselheiros locais, mas a participação foi se tornando mais expressiva no decorrer do trabalho, chegando a 60 pessoas no último encontro.

Para introduzir a discussão sobre a organização do sistema público de saúde, foram abordados nos encontros a história do nascimento do SUS, seus princípios norteadores e a importância do controle social.

Em um segundo momento, outros assuntos relevantes para problematizar a discussão foram tratados, como as características da área de abrangência e as relações com as condições de saúde do bairro, buscando assim envolver os membros do Conselho Local de Saúde e também outros trabalhadores e usuários da UBS.

Essa iniciativa levou-os a assumirem o papel de protagonistas na construção de um novo modelo de assistência à saúde, pois, até então, estes, em sua maioria, se colocavam de forma passiva no processo por falta de informações sobre seus direitos e deveres.

Após essa etapa, algumas mudanças foram sentidas: o Conselho Local de Saúde tornou-se mais representativo, iniciou-se um planejamento local e os trabalhadores da UBS mostraram-se mais interessados em discutir estratégias para a melhoria do trabalho. A partir dessas discussões havia condições para realizar um mapeamento das necessidades e das potencialidades da comunidade, para que o planejamento direcionasse as ações futuras.

A partir desse despertar da cidadania, o terreno havia sido trabalhado para que fosse possível aflorar uma nova forma de gestão no local, passando-se a sentir as proposições do planejamento como uma ferramenta de liberdade, trazendo à tona a essência do pensamento matusiano, como expresso na seguinte passagem “(...) à medida que penso enumero possibilidades futuras porque me liberto da cegueira de não saber que posso escolher. (...) Cada liberdade tem um valor diferente para mim e um valor diferente para os outros. Por isso o único planejamento legítimo é o planejamento democrático descentralizado." ( In: Huertas, 1996, p. 18)
Outra ação foi a concretização do colegiado gestor da UBS, que exigiu, por parte dos trabalhadores da unidade, uma reflexão sobre a organização do trabalho, que até então se definia por uma divisão baseada em atribuições específicas a cada categoria profissional.

O colegiado da UBS, composto de um ou mais trabalhadores de cada categoria, configurou-se como fundamental para o desenvolvimento do MAPP, pois permitiu a socialização do desejo de transformar o modelo de assistência à saúde da comunidade local e melhorar as condições de trabalho.

Para assegurar a representação adequada no órgão colegiado, as categorias profissionais foram representadas proporcionalmente, ou seja, quanto maior o número, maior a representação, e legitimamente escolhidos por seus pares. O colegiado reunia-se semanalmente com pautas construídas coletivamente por seus membros nas quais eles traziam suas contribuições a partir das discussões que realizavam com os outros trabalhadores de suas respectivas categorias.

Por seu caráter deliberativo, o colegiado constituía-se como órgão importante de co-gestão, no entanto, não se constituía como um espaço adequado para a execução do MAPP, pois a pauta de suas reuniões demandava discussões para a tomada das decisões sobre o processo organizativo.

Deste fato, aliado à decisão de desenvolver o planejamento com maior número de pessoas, surgiu uma vontade coletiva em se garantir um espaço onde os atores sociais pudessem fortalecer os laços que já existiam e construir novas perspectivas para o trabalho em equipe. Surgiram então as Reuniões Gerais, que se realizavam mensalmente, com a UBS fechada para as atividades normais, mas aberta para receber usuários e trabalhadores que quisessem discutir e agir dentro da ótica do planejamento local, por meio do MAPP.

O MAPP desenvolveu-se na forma de oficinas de trabalho, favorecendo a construção coletiva a partir da apreensão de novos saberes sobre planejamento, processo de trabalho, humanização da assistência, educação permanente, entre outros conceitos e técnicas utilizados para a efetivação da organização da UBS.

Essas reuniões caracterizavam-se como momento de troca de informações, conhecimentos e opiniões, criando a oportunidade de conhecer o outro, e de co- 
nhecer-se diante do outro, aprendizado importante para a realização do trabalho coletivo. Além disso, as reuniões possibilitaram a valorização da equipe a partir dessa troca de informações e das dinâmicas de interação, motivação e confraternização.

Durante o período de 16 meses, os procedimentos para a organização repetiram-se. A cada mês uma equipe de trabalhadores da UBS encarregava-se do preparo da reunião, afixando cartazes de avisos à população, convidando colegas a participar, providenciando materiais de apoio e organizando lanche.

As reuniões dividiam-se em: a) abertura: dinâmica, música, poesia e curiosidades; b) informes: informações do nível central; c) oficinas de trabalho para o desenvolvimento do MAPP; d) encerramento: conclusões e reflexões, motivadas por músicas ou mensagens preparadas pela equipe organizadora da reunião, além da confraternização com lanche especial com a contribuição de todos.

Para a utilização do MAPP, inicialmente buscouse fazer uma discussão sobre suas fases e sua importância, salientando que o desenvolvimento do trabalho necessitaria da compreensão e da dedicação de todos, pois a ansiedade em ver os problemas resolvidos poderia prejudicar o andamento do processo.

Vale ressaltar que em todas as reuniões os indicadores de saúde da UBS eram avaliados e tratados como resultado do trabalho coletivo. Dessa forma, a melhoria significativa, tanto de produtividade quanto de qualidade do atendimento, motivaram ainda mais a participação dos atores sociais.

No entanto, é necessário considerar os casos de afastamento em relação à proposta da realização de um trabalho coletivo, constatados nos primeiros meses da experiência com alguns pedidos de transferência e até mesmo de demissão por trabalhadores da UBS, além do desligamento de alguns membros do Conselho Local de Saúde. Verificou-se que os estes atores sociais não se identificaram com a proposta.

Assim, é possível considerar que os processos de trabalho, planejados e desenvolvidos coletivamente, podem produzir resultados significativos, que fortalecem os sujeitos em suas ações cotidianas, e ainda que para existir um novo modelo de assistência à saúde, todos os atores sociais envolvidos (usuários, trabalhadores e gestores) devem sentir-se como co-responsáveis pela unidade, pois cada ator social possui importante papel que não pode ser representado por outro, mas com o outro, desenvolvendo, assim, relações de compromisso com sua cidadania.

Apresentar resultados alcançados, durante e depois desse período, torna-se complexo, pois significa apresentar mudanças ocorridas no dia-a-dia, desde as estruturais até as subjetivas - sentidas e vividas de forma única por todos que participaram do processo. Assim elabora Sá (2001, p. 163) sobre os desafios de avaliar estas ações: "Nesse sentido, uma experiência de gestão ou a tentativa de construção de um projeto coletivo não podem ter sua validade e êxito medidos apenas segundo critérios técnico-científicos, mas devem, sobretudo, ser consideradas do ponto de vista de sua validade ética e social".

Consideram-se como resultados mais significativos do processo, o fortalecimento do respeito mútuo e o fortalecimento da cidadania, demonstrado em várias situações do cotidiano da UBS. Pode-se caracterizar como aprendizado organizacional coletivo, o texto elaborado nas oficinas de trabalho e que foi reproduzido em forma de cartazes colados nos murais da UBS. A "missão" da Unidade Básica de Saúde afixada em suas próprias paredes: "Somos uma equipe, trabalhamos para a comunidade. Nossa missão é a prevenção das doenças e a promoção da saúde por meio do respeito ao próximo, atuando com dignidade e satisfação".

Contudo, é importante na mediação do processo organizativo não alimentar ilusões sobre a permanência ou consolidação das mudanças ocorridas, pois este deve ser continuamente avaliado e, se necessário, modificado.

Vale dizer ainda que o aprender organizacional na UBS identificou que a atenção básica pode reorganizar o sistema de saúde, pressupondo o direito de cidadania, além do conceito de saúde a ele subjacente, em que saúde se confunde com a noção de qualidade de vida, em seu sentido mais pleno (L'abbate, 1994).

\section{Considerações Finais}

A experiência relatada foi desenvolvida em um tempo cronológico que pode ser considerado insuficiente para afirmar transformações em relação ao modelo de assistência à saúde. No entanto, é possível verificar que $o$ aprender organizacional da experiência aqui relatada possibilitou a mudança do foco do trabalho, 
isto é, deixou-se de pensar individualmente e em estratégias para executar tarefas impostas, externas aos interesses locais e muitas vezes sem resultados positivos, para iniciar um processo de reflexão sobre a importância do trabalho coletivo para a realização de um planejamento construído a partir dos dados da realidade concreta e da interação da comunidade com a unidade.

Assim, o presente artigo tem como finalidade apontar a possibilidade de a co-gestão constituir-se como forma de organização de uma Unidade Básica de Saúde, despertando a necessidade de rever as concepções de organização do trabalho no campo da atenção básica em saúde, sinalizando a possibilidade da constituição de um modelo que responda aos princípios do SUS.

Salienta-se, porém, que dificuldades existem em todo processo de mudança, principalmente quando elas estão relacionadas à alteração do imaginário social, quanto ao processo coletivo de trabalho. No entanto, estratégias de superação dessa realidade podem ocorrer em propostas onde ocorra o deslocar do foco de referência teórica de um indivíduo centrado nas necessidades para a existência de um sujeito do desejo e das pulsões, caracterizando a própria superação da alienação do trabalho e da noção de cidadania (Birmann, 1997 apud Sá, 2001).

\section{Referências}

AZEVEDO, C. da S. Liderança e processos intersubjetivos em organizações públicas de saúde. Ciência \& Saúde Coletiva, Rio de Janeiro, v. 7, n. 2, p. 349-361, 2002.
BIRMAN, J. Estilo e modernidade em psicanálise. Editora 34. São Paulo, 1997.

BRASIL. Ministério da Saúde. Secretaria de Políticas de Saúde. Departamento de Atenção Básica. Manual para a organização da atenção básica. Brasília, DF: DAS: Coordenadoria de Desenvolvimento de Práticas de Atenção Básica, 1999.

BODSTEIN, R. Atenção básica na agenda da saúde. $C i$ ência \& Saúde Coletiva, Rio de Janeiro, v. 7, n. 3, p. 401412, 2002.

HUERTAS, F. O Método PES: entrevista com Matus. São Paulo: Fundap, 1996.

L'ABBATE, S. Educação em saúde: uma nova abordagem. Cadernos de Saúde Pública, Rio de Janeiro, v. 1o, n. 4, p. 481-490, 1994 .

MEHRY, E. E. Introdução ao debate sobre os componentes da caixa de ferramentas dos gestores em saúde. Disponível em: <http://dtr2002.saude.gov.br/versus /varal/caderno/oo5.html>. Acesso em: o6 jun. 2005.

PERUZZO, C. K. Comunicação nos movimentos populares: a participação na construção da cidadania. Petrópolis: Vozes, 1998.

SÁ, M. de C. Subjetividade e projetos coletivos: malestar e governabilidade nas organizações de saúde. Ciência \& Saúde Coletiva, Rio de Janeiro, v. 6, n. 1, p. 151-164, 2001.

URIBE, F. J. Reflexões sobre a subjetividade na gestão a partir do paradigma da organização que aprende. Ciência \& Saúde Coletiva, Rio de Janeiro, v. 6, n. 1, p. 209-219, 2001. 